\title{
Форстеритовые углеродсодержащие материалы на магнийфосфатной связке
}

\section{Белогурова О.А., Саварина М.А., Шарай Т.В.}

Институт химии и технологии редких элементов и минерального сырья им. И.В. Тананаева КНЦ РАН, Anamumbl,o.belogurova@ksc.ru

Аннотация. Отходы горного производства - источник ценных полезных ископаемых. Для осуществления рационального и комплексного использования этого сырья проводят исследование техникотехнологической, экономической и экологической эффективности. Из углеродсодержащих гранул и брикета на основе форстеритового концентрата, полученного из отходов обогатительного производства Ковдорского ГОКа, на магнийфосфатном цементе получены бетоны со следующими характеристиками: плотность 910-1700 кг/м³, прочность - до 10 МПа. Выявлены экспериментальные зависимости плотности и прочности от соотношения гранулы/брикет.

Ключевые слова: форстеритовый концентрат, углерод, неформованный материал, магнийфосфатная связка, лигносульфонат, конструкционно-теплоизоляционный бетон.

\section{Forsterite carbon-containing materials on magnesium phosphate bond}

\section{Belogurova O.A., Savarina M.A., Sharai T.V.}

Tananaev Institute of Chemistry and Technology of Rare Elements and Mineral Raw Materials of the Kola Science Centre, RAS, Apatity, o.belogurova@ksc.ru

Abstract. Mining waste is a source of valuable minerals. For the implementation of rational and integrated use, a detailed study of technical, technological, economic and environmental efficiency is carried out. Concrete from carbon-containing granules and briquette based on forsterite concentrate of the Kovdorsky mining and processing plant on magnesium phosphate cements with the following characteristics: density $910-1700 \mathrm{~kg} / \mathrm{m}^{3}$, strength - up to $10 \mathrm{MPa}$ was obtained. Experimental dependences of density and strength on the granules / briquette ratio were revealed.

Keywords: forsterite concentrate, carbon, unshaped material, magnesium phosphate bond, lignosulfonate, structural and thermal insulation concrete.

Возможное использование техногенных минеральных образований подразделяется на два направления: доизвлечение основных полезных компонентов (металлов и неметаллов), которые не могли быть извлечены ранее при существовавшем уровне развития техники и технологии; нетрадиционное использование сырья, которое не предполагалось ранее при утверждении запасов «первичных» месторождений (например, в качестве стройматериалов и др.).

В настоящее время огромное внимание уделяется «зеленым» цементным материалам. Известно, что производство портландцемента является вторым по величине источником углекислого газа. Считают, что магнийфосфатный цемент является экологически чистым материалом и способен частично заменить портландцемент (М. А. Наque и др., 2019).

Конструкционно-теплоизоляционные бетоны на пористых заполнителях имеют среднюю

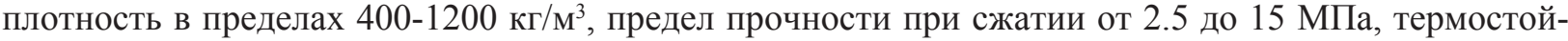
кость 25-35 воздушных теплосмен, температура применения $1000-1600^{\circ} \mathrm{C}$. Такие бетоны можно применять в виде эффективной теплоизоляции тепловых агрегатов взамен штучных дорогостоящих ультралегковесов. Бетоны фосфатного твердения можно использовать как в монолитном варианте, так и в виде отдельных сборных блоков.

В огнеупорах применение магнийфосфатных цементов связано со свойством холодного схватывания для образования продуктов, устойчивых при высоких температурах. Образование фосфа-

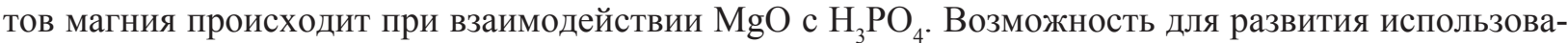
ния магнийфосфатных цементов расширилась с появлением производства намертво обожженного 
$\mathrm{MgO}$, с пониженной реакционной способностью, что сделало их подходящими для применения в строительстве и в качестве огнеупорных связок для литейных форм.

Finch и Sharp обнаружили, что, начиная с водной смеси $\mathrm{MgO}: \mathrm{H}_{3} \mathrm{PO}_{4}=1: 1$, образуется твердый продукт, но стехиометрия реакции не соблюдается из-за неполной реакции $\mathrm{MgO}$, что приводило к соотношению 1:2, как показано в уравнении (Finch T. и др., 1989):

$$
\mathrm{MgO}+2 \mathrm{H}_{3} \mathrm{PO}_{4}+\mathrm{H}_{2} \mathrm{O} \rightarrow \mathrm{Mg}\left(\mathrm{H}_{2} \mathrm{PO}_{4}\right)_{2} \cdot 2 \mathrm{H}_{2} \mathrm{O} .
$$

Для образования нерастворимого продукта с соотношением $\mathrm{Mg} / \mathrm{P}=1: 1$ обычно требуется избыток $\mathrm{MgO}$, причем реакция протекает по уравнению (Hipedinger N.E. и др., 2002):

$$
\mathrm{MgO}+\mathrm{H}_{3} \mathrm{PO}_{4}+2 \mathrm{H}_{2} \mathrm{O} \rightarrow \mathrm{MgHPO}_{4} \cdot 3 \mathrm{H}_{2} \mathrm{O} .
$$

Это взаимодействие сильно экзотермично, что порождает практические проблемы.

Исследователи дают разноречивые сведения по составу соединений, образующихся в бетонах на магнийфосфатной связке, и температуре перехода одного соединения в другое (Soudee E., 1999; Хорошавин Л.Б., 1990; Судакас Л.Г., 2008; N. Yang и др., 2014; Y. Li и др., 2015).

Цель работы - получить углеродсодержащий конструкционно-теплоизоляционный бетон из отходов обогатительного производства Ковдорского ГОКа на магнийфосфатной связке.

Задачи: оценить степень влияния составов шихты и применяемой связки на свойства легких бетонов; установить фосфатные соединения, получающиеся при взаимодействии компонентов шихты и связки; разработать технологию углеродсодержащих легких бетонов на основе форстеритового концентрата.

По «генезису» и форме накопления технологические отходы горнорудного производства можно условно разделить на две группы - «мокрые» и «сухие». На Ковдорском ГОКе к первой группе относятся уложенные в хвостохранилище отходы обогатительного производства: мелкие сильнообводненные пески, содержащие остаточные концентрации основных полезных компонентов, а также не извлеченные в производственном процессе по технологическим, экономическим или конъюнктурным причинам ценные или потенциально ценные примеси (например, минерал форстерит с содержанием до $50 \% \mathrm{MgO}$ ). Ко второй группе отнесены отвалы-склады бедных и забалансовых руд разрабатываемых месторождений (Петрик А.И. и др., 2012).

Химический анализ форстеритового концентрата из отходов обогатительного производства, мас. \%: $\mathrm{MgO}$ - 43-48; $\mathrm{SiO}_{2}-33-39 ; \mathrm{FeO}$ - 4.4-5.3; $\mathrm{Fe}_{2} \mathrm{O}_{3}$ - 0.8-5.9; $\mathrm{CaO}$ - 0.6-2.4; п.п.п. - 0.1-1.5.

Гранулометрия сырого форстеритового концентрата, мас.\%: (>0.2мм) -1, (-0.2+0.16 мм) -7, $(-0.16+0.1$ мм) $-48,(-0.1+0.063)-25,(-0.0630+0.05$ мм $)-5,(<0.05$ мм $)-14$.

При формировании микрогранул из смесей электродного графита с тонкомолотыми порошками форстеритового концентрата существует возможность получения более благоприятной формы частиц, что должно обеспечить высокие реологические свойства легких бетонов.

Состав шихты для гранул, мас. \%: 50 - форстеритовый концентрат, 25 -электродный графит, 25 - каустический магнезит.

Получение гранул: шихту для гранул подвергают помолу в виброистирателе ИВ 1 , для получения фракции $<0.063$ мм, добавляют $\mathrm{MgCl}_{2} \cdot 6 \mathrm{H}_{2} \mathrm{O}$ ( плотность 1.259 г/ $\left.\mathrm{cm}^{3}\right)$, протирают через сито 1 мм, опудривают алюминием, высушивают, обжигают при $1000^{\circ} \mathrm{C}$ в восстановительной среде.

В состав шихты для легкого бетона кроме углеродсодержащих гранул из форстерита входит брикет.

Состав брикета, мас. \%: 50 - форстеритовый концентрат $<0.2$ мм и 15 форстеритовый концентрат $<0.063$ мм, $35-$ бой магнезитовых изделий $<0.2$ мм.

Технологическая схема получения брикета: шихта определенного состава перемешивается, вводится связка (поливиниловый спирт), прессуется под давлением 50-70 МПа, высушивается в естественных условиях в течение суток. Затем обжигается при температуре 1400. Полученный брикет дробят с получением фракций $<3$ мм, часть подвергают помолу в виброистирателе ИВ 1 , для получения фракции $<0.063$ мм. 
Гранулометрия раздробленного брикета, мас. \%: $(-3+2.5$ мм $)-1,(-2.5+1.6$ мм $)-14$, $(-1.6+1$ мм $)-9,(-1+0.63$ мм $)-7,(-0.63+0.4$ мм $)-6,(-0.4+0.315$ мм $)-10,(-0.315+0.2$ мм $)-15$, $(-0.2+0.16$ мм $)-8,(-0.16+0.063$ мм $)-14,(<0.063$ мм $)-16$.

Рентгенофазовый анализ, полученных легких бетонов, проводили на дифрактометре ДРФ -2 (СuК -излучение). Фрактографические исследования выполнены на растровом электронном микроскопе с использованием SEM LEO 420.

Технические требования к конструкционно-теплоизоляционным бетонам предъявляют согласно ГОСТ 34470-2018 «Бетоны огнеупорные» и ГОСТ 25820-2014 «Бетоны легкие». Прочность определяют по ГОСТ 10180-2012 «Бетоны. Методы определения прочности по контрольным образцам», плотность по ГОСТ 52541-2006 «Бетоны огнеупорные. Подготовка образцов для испытаний»

Выявлены экспериментальные зависимости плотности и прочности, изменения объема после термообработки углеродсодержащего форстеритового бетона от количества гранул и тонкой фракции брикета в шихте, добавок к фосфатной связке.

Вяжущим компонентом для бетонов из гранул на основе форстеритового концентрата, послужил фосфат магния, получаемый из магния углекислого основного $\mathrm{Mg}_{5}\left(\mathrm{CO}_{3}\right)_{4}(\mathrm{OH})_{2} \cdot 4 \mathrm{H}_{2} \mathrm{O}$ согласно реакции:

$$
4 \mathrm{MgCO}_{3} \cdot \mathrm{Mg}(\mathrm{OH})_{2} \cdot 4 \mathrm{H}_{2} \mathrm{O}+10 \mathrm{H}_{3} \mathrm{PO}_{4} \rightarrow 5\left[\mathrm{Mg}\left(\mathrm{H}_{2} \mathrm{PO}_{4}\right)_{2} \cdot 2 \mathrm{H}_{2} \mathrm{O}\right]+4 \mathrm{CO}_{2}
$$

Для получения легкого бетона смесь на магнийфосфатной связке (плотность 1.50 г/см³) заливают в разъемные металлические формы высотой 45 мм. Их выдерживают в течение 1 дня, затем формы разбирают и образцы выдерживают на воздухе еще 6 дней. Далее образцы термообрабатывают при $450^{\circ} \mathrm{C}$ и при $1000^{\circ} \mathrm{C}$ с выдержкой 2 ч. при максимальной температуре.

С возрастанием количества брикета в шихте растет прочность легкого бетона, наибольшая прочность у образца из шихты (40 \% гранулы $+60 \%$ брикет $<0.063$ мм). Плотность после обжига при $450{ }^{\circ} \mathrm{C}$ уменьшается и происходит усадка 2.7- 4.1\%. На рисунках 1,2 представлены зависимости показателей прочности и плотности от соотношения гранул и брикета в шихте.

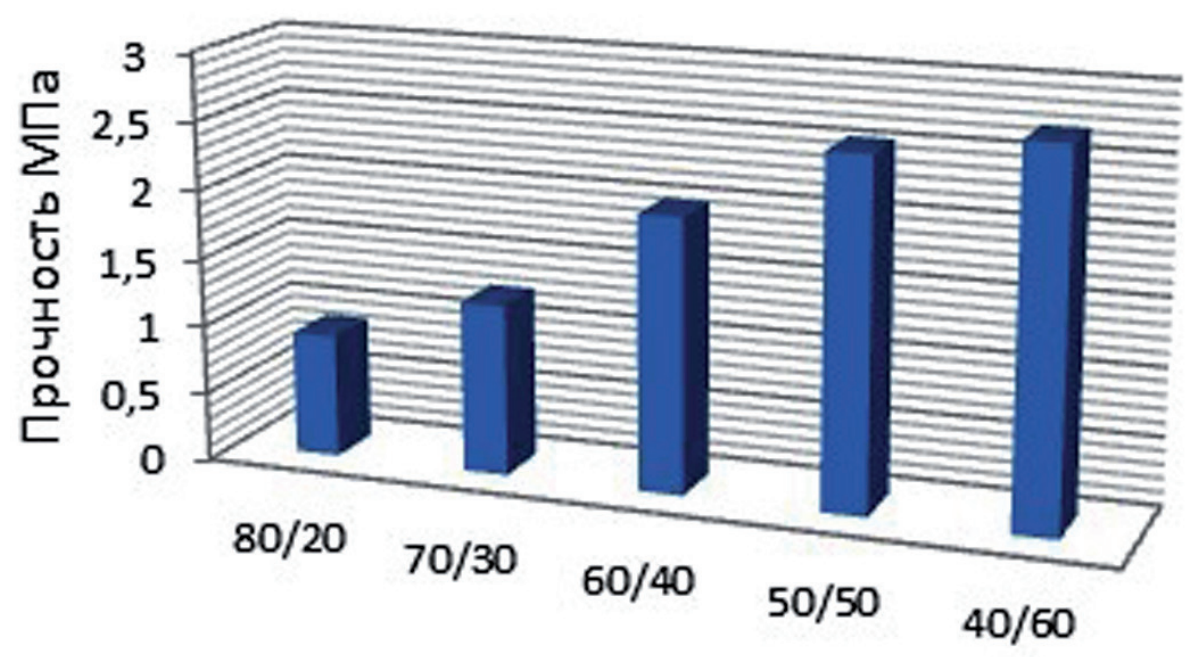

\section{Соотношение гранулы/брикет}

Рис. 1. Влияние соотношений гранулы/брикет на прочность бетона на магнийфосфатной связке (после 28 суток твердения).

Fig. 1. Influence of the granule / briquette ratios on the strength of concrete on a magnesium phosphate bond (after 28 days of hardening). 


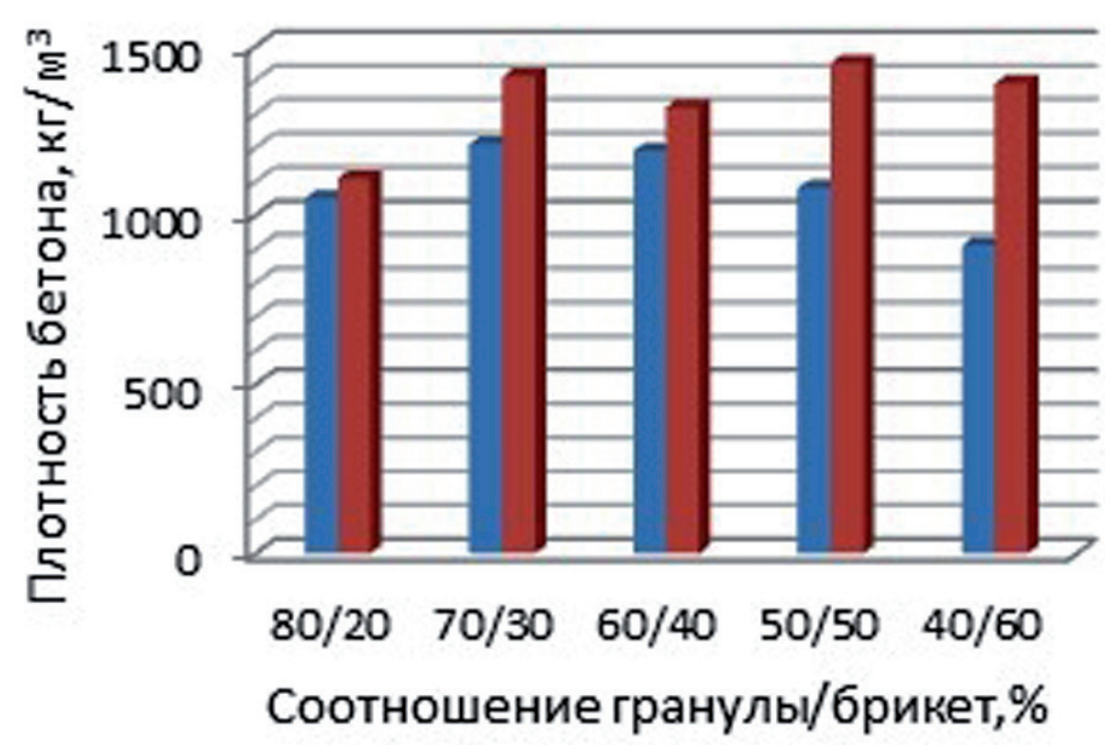

\section{7 суток}

28 суток

Рис. 2. Влияние соотношений гранулы/брикет на плотность бетона на магнийфосфатной связке (в легенде количество суток твердения бетона).

Fig. 2. Influence of the granule / briquette ratios on the density of concrete on a magnesium phosphate bond (in the legend, the number of days of concrete hardening).

Для фосфатных связок схемы превращений цементирующей части неоднозначны и в композициях присутствуют фазы переменного состава, новообразования по большей части аморфны и лишь при нагревании склонны к кристаллизации и взаимодействию с зернами наполнителя. Микроструктура подвергается значительным изменениям при термообработке.

Анализ данных рентгенофазового анализа легких бетонов различных составов показывает наличие форстерита, периклаза, ньюбериита $\mathrm{MgHPO}_{4} \cdot 3 \mathrm{H}_{2} \mathrm{O}$.

Были проведены исследования фазового состава образцов в зависимости от термообработки смеси. Исходя из данных рентгенофазового анализа ньюбериит при $150^{\circ} \mathrm{C}$ перешел в моногидрат гидроортофосфата $\mathrm{MgHPO}_{4} \cdot \mathrm{H}_{2} \mathrm{O}$. При $200^{\circ} \mathrm{C} \mathrm{MgHPO}_{4} \cdot \mathrm{H}_{2} \mathrm{O}$ преобразовался в дигидропирофосфат $\mathrm{MgH}_{2} \mathrm{P}_{2} \mathrm{O}_{7}$. После $400^{\circ} \mathrm{C}$ на рентгенограмме отмечены линии тетраметафосфата $\mathrm{Mg}_{2} \mathrm{P}_{4} \mathrm{O}_{12}$, от $700^{\circ} \mathrm{C}$ - ортофосфата $\mathrm{Mg}_{3}\left(\mathrm{PO}_{4}\right)_{2}$ :

$$
\mathrm{MgHPO}_{4} \cdot 3 \mathrm{H}_{2} \mathrm{O} \rightarrow{ }^{\left(150^{\circ} \mathrm{C}\right)} \mathrm{MgHPO}_{4} \cdot \mathrm{H}_{2} \mathrm{O} \rightarrow{ }^{\left(200^{\circ} \mathrm{C}\right)} \mathrm{MgH}_{2} \mathrm{P}_{2} \mathrm{O}_{7} \rightarrow^{\left(400^{\circ} \mathrm{C}\right)} \mathrm{Mg}_{2} \mathrm{P}_{4} \mathrm{O}_{12} \rightarrow{ }^{\left(700^{\circ} \mathrm{C}\right)} \mathrm{Mg}_{3}\left(\mathrm{PO}_{4}\right)_{2}
$$

Прочность образцов растет с увеличением содержания брикета. Реакция с фосфатом магния идет бурно, было решено провести испытания с замедлителем, например, лигносульфонатом. Такая комбинированная связка обеспечивает более медленное взаимодействие компонентов при постепенном выделении тепла. Соотношение магнийфосфатная связка/ лигносульфонат было следующим: 80/20, 70/30, 60/40, 50/50. На рисунках 3, 4 представлены зависимости показателей прочности и плотности легкого бетона от соотношения гранул и брикета в шихте, а также состава комбинированной связки.

Отмечено, что при содержании в шихте брикета 20-30 \% увеличивается показатель прочности для образцов с комбинированным связующим при соотношении магнийфосфатная связка/ лигносульфонат $=50: 50$. В то время как, при содержании в шихте брикета 40-60 \% увеличивается показатель прочности для образцов с комбинированной связкой магнийфосфатная связка/ лигносульфонат $=80: 20$. С уменьшением содержания магнийфосфатной связки значения прочности падают.

Введение в связку лигносульфоната положительно сказалось на свойствах бетонов, плотность и прочность увеличились. Наибольшая прочность (10 МПа) достигнута у образца из шихты (40 \% гранулы $+60 \%$ брикет $<0.063$ мм) при соотношении магнийфосфатная связка/ лигносульфонат $=80 / 20$. 


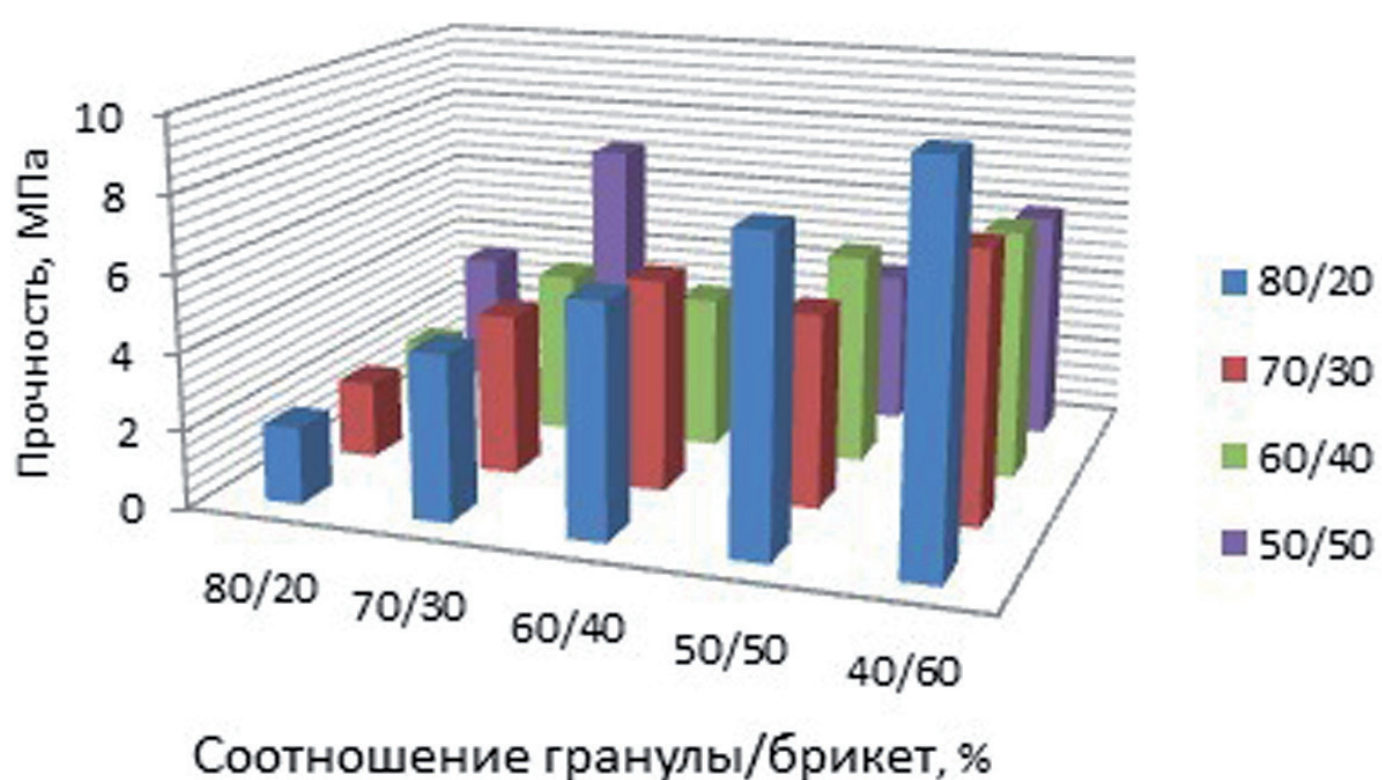

Рис. 3. Влияние соотношений гранулы / брикет и магнийфосфатная связка/лигносульфонат на прочность бетона на комбинированной связке (в легенде соотношение магнийфосфатная связка/лигносульфонат).

Fig. 3. Influence of the ratio of granules / briquettes and magnesium phosphate bond / lignosulfonate on the strength of concrete with a combined bond (in the legend, the ratio of magnesium phosphate bond / lignosulfonate).

\section{Выводы}

Разработана технология конструкционно-теплоизоляционных бетонов из углеродсодержащих гранул и брикета на основе форстеритового концентрата, полученного из отходов обогатительного производства Ковдорского ГОКа, с использованием цементов из магниевых фосфатов.

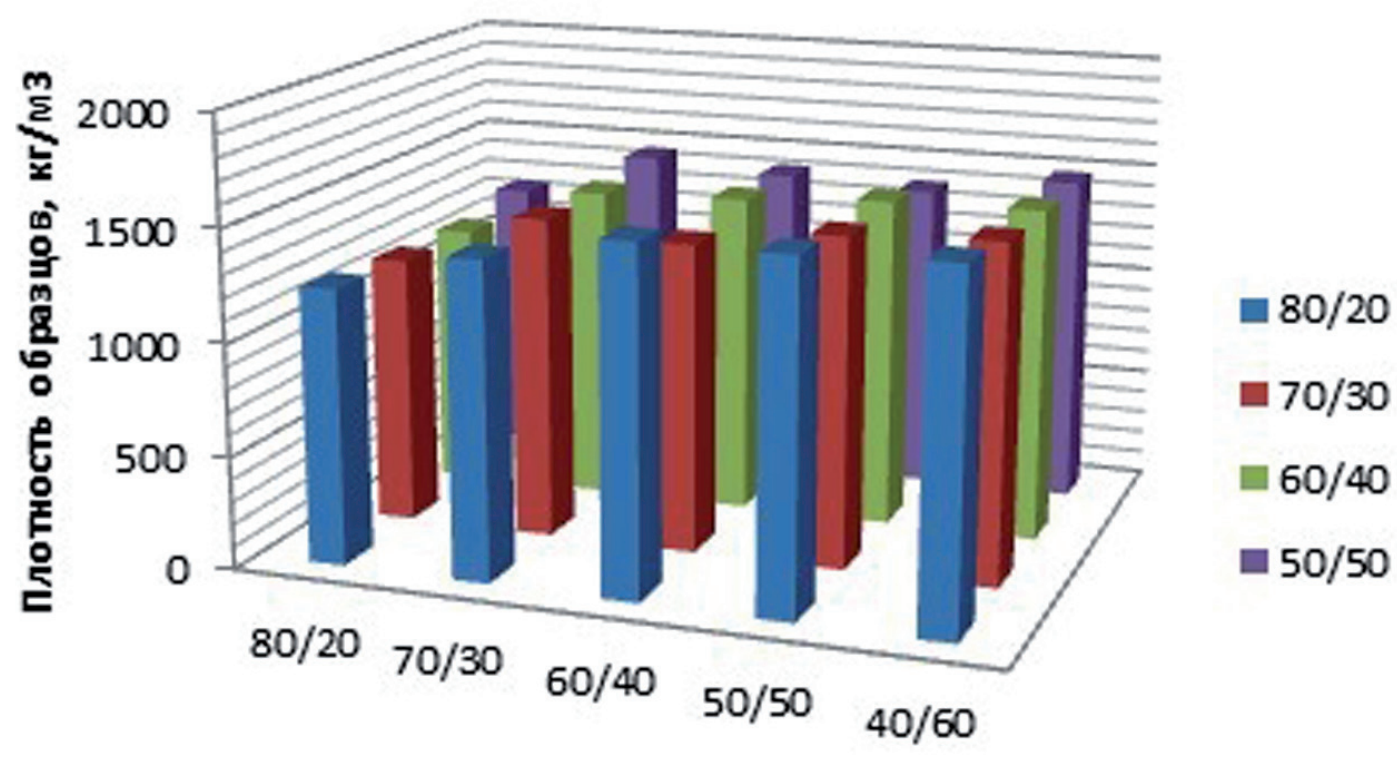

\section{Соотношение гранулы/брикет, \%}

Рис. 4. Влияние соотношения гранулы/брикет и магнийфосфатная связка / лигносульфонат на плотность бетона на комбинированной связке (в легенде соотношение магнийфосфатная связка / лигносульфонат).

Fig. 4. Influence of the ratio of granules / briquettes and magnesium phosphate bond / lignosulfonate on the density of concrete on a combined bond (in the legend, the ratio of magnesium phosphate bond/ lignosulfonate). 
Отмечено, что прочность легкого бетона на магнийфосфатной связке увеличивается с возрастанием количества брикета в шихте, наибольшая прочность (3 МПа) у образца из шихты (40\% гранулы $+60 \%$ брикет $<0.063$ мм). Согласно данным рентгенофазового анализа в этих материалах присутствует форстерит, периклаз, ньюбериит $\mathrm{MgHPO}_{4} \cdot 3 \mathrm{H}_{2} \mathrm{O}$. Последний после $150^{\circ} \mathrm{C}$ переходит в моногидрат гидроортофосфата $\mathrm{MgHPO}_{4} \cdot \mathrm{H}_{2} \mathrm{O}$, после $200^{\circ} \mathrm{C}$ появляется дигидропирофосфат $\mathrm{MgH}_{2} \mathrm{P}_{2} \mathrm{O}_{7}$, после $400^{\circ} \mathrm{C}$ отмечен тетраметафосфат $\mathrm{Mg}_{2} \mathrm{P}_{4} \mathrm{O}_{12}$ и после $700^{\circ} \mathrm{C}$ - ортофосфат $\mathrm{Mg}_{3}\left(\mathrm{PO}_{4}\right)_{2}$.

Увеличения показателей плотности и прочности можно достичь при использовании комбинированной связки из $\mathrm{Mg}\left(\mathrm{H}_{2} \mathrm{PO}_{4}\right)_{2} \cdot 2 \mathrm{H}_{2} \mathrm{O}$ и лигносульфоната.

Углеродсодержащие легкие бетоны на цементах из магниевых фосфатов предлагается использовать в сталелитейной промышленности.

\section{Литература}

1. Петрик А.И., Быховец А.Н., Сохарев В.А., Переин В.Н., Сердюков А.П. Модернизация минеральносырьевой базы в стратегии долгосрочного развития Ковдорского ГОКа // Горный журнал. 2012. №10. C. $12-17$.

2. Судакас Л.Г. Фосфатные вяжущие системы. СПб. Изд-во: РИА «Квинтет». 2008. 260 с.

3. Хорошавин Л.Б. Магнезиальные бетоны. М. Изд-во: Металлургия. 1990. С. 68.

4. M.A. Haque, B. Chen Research progresses on magnesium phosphate cement: A review // Construction and building materials. 2019. V. 211. P. 885-898. https://doi.org/10.1016/j.conbuildmat.2019.03.304.

5. Hipedinger N.E., Scian A.N., Aglietti E.F. Magnesia-phosphate bond for cold-setting cordierite-based refractories // Cem. Concr. Res. 2002. V. 32. P. 675-682.

6. Finch T., Sharp J.H. Chemical reactions between magnesia and aluminium orthophosphate to form magnesiaphosphate cements // J. Mater. Sci.1989. V. 24. P. 4379-4386.

7. Y. Li, C. Bing New Type of Super-Lightweight Magnesium Phosphate Cement Foamed Concrete //Journal of Materials in Civil Engineering. 2015. V. 27. issue 1. https://doi.org/10.1061/(ASCE)MT.1943-5533.0001044.

8. Soudee E. Liants phosphomagnesiens - mecaniqme de prise et durabilite: diss. Doctorat.- Lyon. 1999. 266 p.

9. N. Yang, C. Shi, J. Yang, Y. Chang Research Progresses in Magnesium Phosphate Cement-Based Materials // Journal of Materials in Civil Engineering. 2014. V. 26(10). P. 1-8. DOI: 10.1061/(ASCE)MT.1943-5533.0000971. 